\title{
STUDY OF CHANGES IN COLOUR AND MORPHOLOGICAL PARAM- ETERS IN HUMAN CATARACTOUS LENS NUCLEI
}

\author{
Shashank Vedpathak *1, S.S. Dhapate ${ }^{2}$, Sandeep Bendale ${ }^{3}$. \\ ${ }^{* 1}$ Associate Professor, Department of Anatomy, MIMER Medical College, Talegaon, Dabhade, \\ Pune, Maharashtra, India. \\ ${ }^{2}$ Professor and HOD, Department of Anatomy, S.R.T.R. Medical College, Ambajogai, Maharashtra, \\ India.
}

${ }^{3}$ Assistant Professor, Department of Radiodiagnosis, MIMER Medical College, Talegaon, Dabhade, Pune, Maharashtra, India.

\section{ABSTRACT}

Introduction: Opacification of the lens of the eye which makes it blind is called cataract. This study deals with the cataractous lenses removed from the patients residing in a rural area like marathwada region and was done at S.R.T.R. Medical College Ambajogai. This topic was chosen as this type of study has never been done before in this region. From anatomical point of view the morphologic features of the lens nuclei removed by extracapsular cataract extraction method are studied and compared with age and sex of patient.

Materials and methods: The lens nuclei removed by extracapsular extraction method were collected in plain bulbs and preserved in $10 \%$ formalin for morphological observations. Detailed case history of the patient is recorded. Colour of lens nuclei was recorded and changes in diameter, thickness and wet weight of lens nuclei according to colour were studied. Diameter and thickness was measured with vernier caliper while weight is measured with two pan scientific balance. Pirie's classification was used to divide the lens in four groups.

Results: According to our study mean diameter of lens nuclei goes on increasing from Group I to Group IV in both men and women and similar findings are observed for mean thickness and weight of lens nuclei in both male and female.

Discussion: Our study found statistically significant increase in thickness, diameter and weight of lens as the colour of lens nuclei deepens. Our findings are compared with other workers. These morphological findings may be useful for the ophthalmologists to correlate with their clinical observations.

Conclusion: Our study found that morphological parameters of lens change as its colour deepens.

KEY WORDS: Colour, Cataract, Diameter, Lens, Thickness, Weight.

Corresponding Author: Dr Shashank Vedpathak, Department of Anatomy, MIMER Medical College, Talegaon Dabhade, Pune, Maharashtra, India. Mobile no - 9604200292

E-Mail: sbvedpathak@gmail.com

Access this Article online

Quick Response code

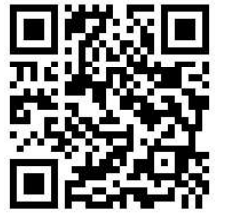

DOI: $10.16965 /$ ijar.2019.317

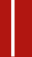

\begin{tabular}{|c|c|c|}
\hline \multicolumn{3}{|c|}{$\begin{array}{l}\text { International Journal of Anatomy and Research } \\
\begin{array}{l}\text { ICV for 2016 ISSN (E) 2321-4287 | ISSN (P) 2321-8967 }\end{array}\end{array}$} \\
\hline \multicolumn{3}{|c|}{ Article Information } \\
\hline $\begin{array}{l}\text { Received: } 20 \text { Sep } 2019 \\
\text { Peer Review: } 20 \text { Sep } 2019 \\
\text { Revised: None }\end{array}$ & $\begin{array}{l}\text { Accepted: } 09 \text { Oct } \\
\text { Published (O): } 05 \\
\text { Published (P): } 05\end{array}$ & 2019 \\
\hline
\end{tabular}

\section{INTRODUCTION}

A cataract is the clouding of the lens of the eye. It is a leading cause of blindness in the world. During cataractogenesis there is gradual loss of vision which progresses to severe visual impairment. This gradual loss of vision is due to gradual loss of transparency. Since, transparency of lens is so highly dependent on protein order and structural integrity, relatively small changes in any of these might lead to increasing 
nuclear pigmentation and development of opacification. Most of these changes can take place during aging and cataract development [1].

Every aging person develops morphological lens changes. However, it is remarkable that only in some patients these circumscribed opacities progress to mature cataracts and that the time of occurrence varies so widely. Furthermore it is even more remarkable that these age related lens changes can have such different morphological manifestations and it is difficult to understand why opacification in some patients is more intense than others. These modifications in morphological parameters of cataractous lenses are not inevitably concurrent with our fate of aging but are caused by other superimposed influences ${ }^{2}$ and despite intensive research going on throughout the world we know little about the fundamental changes which determine cataractogenesis [1].

\section{MATERIALS AND METHODS}

This study was conducted in S.R.T.R. Medical College Ambajogai. Detailed case history of the patient undergoing extracapsular cataract extraction was recorded prior to surgery. Cataractous lens nuclei were collected after extracapsular cataract extractions performed in ophthalmic OT. About 350 lens nuclei were collected and were stored in $10 \%$ formalin in separate plain bulbs. Many lens nuclei which were distorted or cut in pieces were excluded and only those which have smooth margins and regular surface were included in the study. All lenses were handled carefully and following morphological parameters were studied in all the collected lenses -1 ) colour of the lens nucleus; 2) diameter of the lens nucleus; 3 ) central thickness of the lens nucleus. 4) Weight of the lens nucleus.

The term nucleus used here is to mean the region located surgically by the marked change in texture from the soft outer layers of the cortex to the hardened core. The nuclei examined contained the adult nucleus and possibly a portion of the hardened inner cortex. ${ }^{3}$ All of the lens nuclei had some general characteristics namely:

1. Yellow color in the range pale yellow to dark yellow-brown.
2. Opaque central region usually symmetrically located but sometimes slightly off center

\section{Transparent rim in many of them.}

Depending on colour of the lens nucleus; the collected lenses were graded according to Pirie's classification [4]. Pirie's classification was used because it is based simply on the colour of the lens after extraction. The lenses were divided into four groups according to the visibility and color of the lens nucleus. The cataractous lenses varied from a pale yellow to almost brown black [5]. The colour was determined in bright daylight by keeping the lens against a white background.

Table 1: Pirie's classification [5].

\begin{tabular}{|c|c|}
\hline Group & Characteristics of lens \\
\hline I & Uniform pale yellow \\
\hline II & Pale cortex with visible nucleus \\
\hline III & Pale cortex with hazy brown nucleus \\
\hline IV & Pale cortex with deep brown nucleus \\
\hline
\end{tabular}

The diameter of all lenses was measured with vernier caliper [6] to the accuracy of $0.05 \mathrm{~mm}^{7}$ The diameter was measured in two different directions for each lens; a horizontal and vertical direction; and the average was calculated. Thickness of the cataractous lenses was also measured using vernier caliper to the accuracy of $0.05 \mathrm{~mm}$. The wet weight of the lenses was calculated by using Two Pan Scientific Balance.

Fig. 1: Showing lens nuclei stored in plain bulbs in formalin.

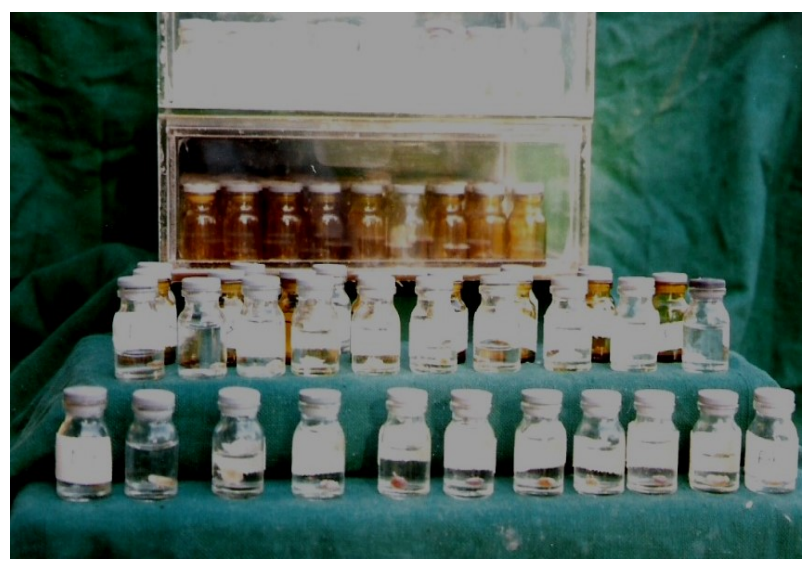

\section{RESULTS AND OBSERVATIONS}

The colour, diameter, thickness and weight of all lens nuclei are recorded and these findings are tabulated. Our observations are them compared with those of different workers. 
Table 2: Showing no. of cases in each colour group.

\begin{tabular}{|c|c|c|c|c|c|}
\hline \multirow{2}{*}{ Colour } & \multicolumn{2}{|c|}{ Male } & \multicolumn{2}{c|}{ Female } & Total \\
\cline { 2 - 6 } & Cases & percentage & cases & percentage & Cases \\
\hline Group I & 49 & 28.99 & 44 & 24.31 & 93 \\
\hline Group II & 40 & 23.67 & 45 & 24.86 & 85 \\
\hline Group III & 49 & 28.99 & 60 & 33.15 & 109 \\
\hline Group IV & 31 & 18.34 & 32 & 17.68 & 63 \\
\hline Total & 169 & 100 & 181 & 100 & 350 \\
\hline
\end{tabular}

Table 2 shows the distribution of cases according to colour of the nucleus. Nuclei are divided into four groups as per Pirie's classification and number of cases in each group are tabulated.

Table 3: Mean diameter $(\mathrm{mm})$ of each colour group of lens nucleus.

\begin{tabular}{|c|c|c|c|c|}
\hline \multirow{2}{*}{ Colour group } & \multicolumn{2}{|c|}{ Male } & \multicolumn{2}{c|}{ Female } \\
\cline { 2 - 5 } & Diameter & $\underline{\underline{ \pm} \text { S.D. }}$ & Diameter & $\underline{ \pm \text { S.D. }}$ \\
\hline Group I & 5.08 & 0.13 & 4.97 & 0.08 \\
\hline Group II & 6.25 & 0.09 & 6.02 & 0.12 \\
\hline Group III & 7.32 & 0.12 & 7.09 & 0.07 \\
\hline Group IV & 8.35 & 0.1 & 8.07 & 0.09 \\
\hline
\end{tabular}

Values for mean diameter of nucleus show increase as per the colour of nucleus deepens. When the values for mean diameter in each colour group are statistically compared with the values in next group, then these are found to be statistically significant $(P<0.05)$ both in male and female. Mean diameter values for group I and group IV are statistically highly significant $(P<0.001)$ both in male and female. When the diameter in each group is compared between male and female, they are statistically insignificant.

Table 4: Showing mean central thickness $(\mathrm{mm})$ of each colour group of lens nucleus.

\begin{tabular}{|c|c|c|c|c|}
\hline \multirow{2}{*}{ Colour } & \multicolumn{2}{|c|}{ Male } & \multicolumn{2}{c|}{ Female } \\
\cline { 2 - 5 } & Thickness & \pm tS.D. & Thickness & $\underline{ \pm}$ S.D. \\
\hline Group I & 2.69 & 0.07 & 2.7 & 0.05 \\
\hline Group II & 3.3 & 0.05 & 3.2 & 0.04 \\
\hline Group III & 3.69 & 0.02 & 3.59 & 0.02 \\
\hline Group IV & 3.9 & 0.02 & 3.88 & 0.03 \\
\hline
\end{tabular}

Table 4 shows that values for mean central thickness of nucleus increase in successive groups of colour. This increase is statistically significant both for male and female $(P<0.05)$. Mean thickness difference between group I and group IV is statistically highly significant $P<0.001$. Mean thickness of same group does not differ much between male and female and are statistically insignificant.
Table 5: Showing mean wet weight $(\mathrm{mg})$ of each colour group of lens nucleus.

\begin{tabular}{|c|c|c|c|c|}
\hline \multirow{2}{*}{ Colour } & \multicolumn{2}{|c|}{ Male } & \multicolumn{2}{c|}{ Female } \\
\cline { 2 - 5 } & Wet weight & \pm \S.D. & Wet weight & \pm \.D. \\
\hline Group I & 66.02 & 1.84 & 64.38 & 1.16 \\
\hline Group II & 80.37 & 1.02 & 74.93 & 0.86 \\
\hline Group III & 89.85 & 0.73 & 84.65 & 1.02 \\
\hline Group IV & 99.64 & 1.08 & 95.28 & 1.05 \\
\hline
\end{tabular}

Values for mean wet weight of nucleus show increase as the colour of nucleus deepens. When the values for mean wet weight in each colour group are statistically compared with the values in next group, then these are found to be statistically significant $(P<0.05)$ both in male and female. Mean wet weight values for group I and group IV are statistically highly significant $(P<0.001)$ both in male and female. When the wet weight in each group is compared between male and female, they are statistically insignificant.

\section{DISCUSSION}

The pathophysiology behind causation of cataracts is complex and yet to be fully understood. In all probability, its pathogenesis is multifactorial involving complex interactions between various physiologic processes. These interactions lead to changes in normal morphology of beautiful transparent lens which gradually loses its transparency leading to advancement of cataract. We have made an attempt to study these changes in the extracted lens nuclei.

In this study, maximum number of male patients are in Group I \& Group III and female in Group III. Group I patients had uniform pale yellow nucleus while group III patients had hazy brown nucleus. When all 350 cases are compared maximum patients are in Group III.

We have found significant correlation between increasing colouration of nucleus and the diameter of nucleus. Mean diameter in each colour group show statistically significant increase both in male and female. This shows that darkening of colour of nucleus occurs simultaneously with increase in diameter of lens so that lenses with maximum diameter are darkest. This finding implies that colour has a more significant \& more stable correlation with diameter of lens $[9,10]$. 
Our study has found similar positive correlation between increasing colouration of nucleus and thickness of nucleus. As shown in table IV, mean thickness in each colour group goes on increasing with deepening of nuclear colour. This finding proves that along with diameter, colour of nucleus has a more significant \& more stable correlation with thickness of lens also $[9,10]$.

These results are in total agreement with those found by Gullapalli et al [9] and $\mathrm{Hu} \mathrm{C}$ et al [10] who state that colour is more reliable indicator and a marker of nuclear diameter and central thickness. We have compared our findings with Gullapalli et al [9].

Table 6: Comparison of colour with diameter and thickness.

\begin{tabular}{|c|c|c|c|c|c|c|}
\hline \multirow{3}{*}{ Colour } & \multicolumn{3}{|c|}{ Mean diameter } & \multicolumn{3}{|c|}{ Mean thickness } \\
\cline { 2 - 4 } & \multirow{2}{*}{ Gullapalli [9] } & \multicolumn{2}{|c|}{ Present study } & \multirow{2}{*}{ Gullapalli [9] } & \multicolumn{2}{|c|}{ Present study } \\
\cline { 3 - 4 } \cline { 6 - 7 } & & Male & female & & Male & female \\
\hline Group I & 6.9 & 5.08 & 4.97 & 2.83 & 2.69 & 2.7 \\
\hline Group II & 7 & 6.25 & 6.02 & 3.03 & 3.3 & 3.2 \\
\hline Group III & 7.28 & 7.32 & 7.09 & 3.21 & 3.69 & 3.59 \\
\hline Group IV & $7.81-8.17$ & 8.35 & 8.07 & $3.38-4.00$ & 3.9 & 3.88 \\
\hline
\end{tabular}

Our study has shown a statistically significant increase in wet weight of lens nuclei with deepening of its colour. This reveals that the weight of lens increases as it darkens.

However we did not find any difference in the diameter, thickness or wet weights in male and female in the respective colour groups. This suggest that the increase in these morphological parameters of lens nucleus is independent of sex.

\section{CONCLUSION}

Our study has shown that the diameter, central thickness and wet weight of lens increases as the colour of lens darkens. So when colour of nucleus is darker, the clinician can expect a larger and thicker lens to be expressed. This finding may be helpful in determining the length of section required in expressing the cataractous lens nucleus.

\section{Conflicts of Interests: None}

How to cite this article: Shashank Vedpathak, S.S. Dhapate, Sandeep Bendale. STUDY OF CHANGES IN COLOUR AND MORPHOLOGICAL PARAMETERS IN HUMAN CATARACTOUS LENS NUCLEI. Int J Anat Res 2019;7(4.2):7119-7122. DOI: 10.16965/ ijar.2019.317

\section{REFERENCES}

[1]. Adler's Physiology of Eye.The Lens, in: Adler's Physiology of Eye by Christopher A. Paterson, Nicholas Delamere, 348-390.

[2]. Shah L. M., Lipid profile in normal human \& senile cataractous lenses, a dissertation submitted for the Medical Biochemistry degree examination of University of Pune.

[3]. Costello M. J., Oliver T. N., Cobo LM.; Cellular architecture in age-related human nuclear cataracts. Invest Ophthalmol Vis Sci. 1992 Oct; 33(11):3209-27.

[4]. J. J. Harding; Free \& protein bound glutathione in normal and cataractous lenses Biochem J, 1970;117:957-960.

[5]. Antoinette Pirie; Colour \& solubility of proteins of human cataracts.Invest Opthalmol Vis Sci, 1968 Dec; 634-650.

[6]. Taylor V. L., al-Ghoul K. J., Lane C. W., Davis V. A., Kuszak J. R., Costello M. J. Morphology of the normal human lens. Invest Ophthalmol Vis Sci. 1996 Jun; 37(7):1396-410.

[7]. Tabandeh H., Thompson G. M., Heyworth P. Lens hardness in mature cataract Eye 1994; 8(4):453-5.

[8]. Dorairaj, S. J., Vatsala V, Vijaya Kumar J, Kesavai R, Sucheethra D.S., Vidyasree, S. Morphometric and Histological Study of Human Cataract Lens; Journal of Anatomical Society of India. 2002;51(1):14-17.

[9]. Gullapalli Vamsi Krishna, Murthy Praveen R, Murthy K. R.; Colour of the nucleus as a marker of nuclear hardness, diameter and central thickness, Indian J Ophthalmol 1995;43:181-184.

[10]. Hu C, Zhang X, Hui Y. The nuclear hardness and associated factors of age-related cataract ; Jpn J ophthalmol. 1997;37(4):467-77. 